\title{
Advent of Renewable Energy Market- Understanding Critical Success Factors in PPA Model
}

\author{
Abhijeet Acharya ${ }^{1}$ \\ ${ }^{1}$ College of Management and Technology, Walden University, Minnesota, USA \\ Correspondence: Abhijeet Acharya, College of Management and Technology, Walden University, Minnesota, \\ USA.
}

Received: January 1, 2021

Accepted: February 6, 2021

Online Published: February 19, 2021

doi:10.5539/eer.v11n1p1

URL: https://doi.org/10.5539/eer.v11n1p1

\begin{abstract}
Under the market reforms, the unbundling of energy systems has opened new areas for value creation at a competitive price, which was impossible in centralized energy markets dominated by utilities. The renewable energy market via Power Purchase Agreement (PPA) has emerged as a realistic business proposition within such reforms. In the last decade, the renewable energy market based on the PPA scheme has seen unprecedented growth in Europe and North America. The falling cost of renewable energy and exigency to achieve energy transition targets have created new opportunities for Independent Power Producers (IPP) via the PPA route. Alongside, the PPA improves bankability and ensures a long-term revenue stream for renewable energy projects in the subsidy-free environment. On the contrary, the complexity of PPA models, market risks, and intermittency of energy generation pose challenges to IPPs and buyers. Considering PPA is an evolving concept, this paper aims to contribute to the existing knowledge on PPAs by analyzing critical success factors in the PPA model. During analysis, the elements that emerged as critical success factors are 1) tariff design, 2) bankability to secure funds, 3) addressing intermittency, and 4) stakeholder engagement. With a focus on regional settings and emerging trends, this paper discussed the rationale for PPA model selection, risk management practices, and strategic partnerships for value creation. During analysis, we also observed that the PPA schemes are driven by local market configuration, demand patterns, and country-specific policies.
\end{abstract}

Keywords: renewable energy, tariff design, power purchase agreement, risk management, strategic partnership

\section{Introduction}

\subsection{Background}

As part of market reforms in the 1990s, the unbundling of the electricity value chain allowed greater market participation (Fuentes-Bracamontes, 2016). Initially, critics argued that such unbundling could result in higher transaction costs. However, the transaction costs due to fragmentation of services were offset by market competition leading to new value propositions and improving overall efficiency (Fuentes-Bracamontes, 2016). Such market reforms have given entry to non-utility energy generators. Over the last two decades, there has been significant growth in non-utility participation in renewable energy generation worldwide. These independent and small-scale energy generators are categorized as IPP, having diverse ownership structures, and usually represented by community groups, social enterprises, municipal bodies, city councils, and private developers. To increase renewable energy diffusion, many countries in Europe provided fixed Feed-in Tariffs (FITs) support, which successfully stimulated renewable energy growth and worked as a financial guarantee for IPPs (Rövekamp, Schöpf, Wagon, Weibelzahl \& Fridgen; 2020). The FIT schemes improved the bankability of renewable energy projects and helped them to secure project funding from financial institutions. However, in 2014 many European countries decided to gradually withdraw FIT schemes for all new renewable projects. Policymakers argued that with the increased diffusion of renewable energy, FIT supports could lead to distorted wholesale electricity market prices. Additionally, the financial burden of existing FITs is levied and passed on to consumers; instead, policymakers advocated market-based policy instruments (Rövekamp et al., 2020). The PPA schemes have emerged as an alternate energy market where IPPs can have long-term revenue visibility. Also, energy buyers or off-takers such as corporate houses, civic bodies, universities, and government organizations enjoy long-term energy price stability and earn green origin certificates. Under PPA, many private companies are procuring renewable energy as part of their sustainability strategy to reduce carbon emissions. Corporate PPAs 
are an effective instrument to mitigate the risks for IPPs (henceforth developers, IPPs, and developers are alternatively used in the existing literature on PPA) and financing parties and, therefore, it can significantly increase renewable energy deployment (WBCSD, 2016). The corporate PPAs has emerged as an innovative driver of renewable energy growth. In North America, corporate PPAs worth $2.78 \mathrm{GW}$ signed in 2017; in the European region, corporate PPAs signed for almost 800 MW in 2017 (IRENA, 2018a). Corporate PPAs gained traction in the Asia-Pacific region, particularly in Australia and India. Australia signed the Murra Warra wind farm 226 MW PPA involving Telstra, Coca-Cola, ANZ Bank, and the University of Melbourne, while India saw corporate PPAs worth $10 \mathrm{MW}$ in 2017 (IRENA, 2018a). Despite promising growth in PPAs, developers find themselves entangled in complex situations due to multiple agency involvement, market risks, and intermittency of power generation. Additionally, due to the lack of a standard framework and realm of knowledge, parties involved in the PPA scheme often struggle to select the most suitable tariff design and safeguard themselves from future risks. Limited understanding of PPA schemes also results in project delays, ultimately impacting renewable energy diffusion.

\subsection{Aim of the Paper}

This paper aims to contribute to the existing knowledge on PPA schemes from the developers' perspective by discussing emerging trends, critical success factors, and tariff design in the PPA model. The paper also discusses the rationale for PPA model selection, risk management practices, and the importance of strategic partnerships. Section 1 highlighted PPA schemes' potential benefits and provided a brief background of challenges and barriers. Section 2 discusses the methodology. In section 3, we discuss the PPA concept and various elements involved in it. We discussed critical success factors in the PPA model by analyzing emerging trends and regional market configurations in section 4. Section 5 discusses PPA execution and risk management strategies employed by developers and buyers in different regions. We also discussed the importance of strategic partnership to improve success rates in PPAs in section 5. Section 6 concludes this paper by highlighting key aspects of PPAs.

\section{Materials and Method}

I conducted a literature review on papers related to the PPA schemes published within the last five years. The literature review helped me develop a conceptual understanding of the PPA model. To get an in-depth knowledge of PPA models, I reviewed publications and reports on PPA development issued by international bodies and intermediary organizations. I analyzed the critical success factors focusing on tariff design, stakeholder engagement, and bankability used by developers. I also reviewed various mitigation strategies adopted in different regions to discern a current trend in risk management practices. From the developer's perspective, I discussed the importance of developing strategic partnerships to improve business viability.

\section{Advent of PPA Concept}

Energy market reforms driven by the unbundling of energy services allowed private market participants to add new value propositions without depending on large utilities. In the new market configuration, community groups, trusts, corporates, municipalities, and private developers can generate their electricity and sell to a buyer at a pre-agreed price, duration, and meeting demand scenarios governed by contractual agreements. PPA concept emerged in the late 2000s when private and public organizations in the USA started procuring electricity directly from private developers, therefore, effectively bypassing utility companies (Schneider Electric, 2019). The primary motivation for a PPA agreement has been long-term price stability for buyers and revenue visibility for the generators. Another driver for PPAs is acquiring renewable Energy Attribute Certificates (EACs) by the buyer in the liberal market where such a certificate tracking mechanism is possible (IRENA, 2018a). The energy attribute systems in Europe are known as Guarantees of Origin (GOs), while in the USA, it is called Renewable Energy Certificates (RECs). In liberal energy markets, customers have the option to select the source and attribute of their electricity. As a contractual instrument, the EAC provides information about the origin of the energy generated, tracked in the market, and allows consumers to claim renewable energy credits to achieve sustainability objectives (IRENA, 2018a). The global cumulative corporate volume of PPAs in 2018 stands $32 \mathrm{GW}$, with a $13.5 \mathrm{GW}$ volume of agreement in 2018 alone (Schneider Electric, 2019).

In addition to private developers, PPA can also provide bankability to smaller renewable generators ( $<5 \mathrm{MW})$ like community energy groups in Europe. FITs provided long-term revenue visibility to smaller community energy organizations driven by a cooperative structure. However, community groups face challenges in securing funding from financial institutions due to a lack of bankability after the withdrawal of FITs in the UK from 2019 (Acharya \& Cave, 2020; Nolden, Barnes, \& Nicholls, 2020). In many European countries where FIT schemes have been abolished, the PPAs have emerged as new business models for community energy organizations. Withdrawal of FIT schemes in Spain, the U.K., and Poland drove small-scale power generators to partner with corporate 
off-takers to explore alternate energy markets (Schneider Electric, 2019). Independent energy suppliers in the UK like Good Energy and Cooperative energy buy electricity from community energy projects through the PPA route (Willis and Simcock, 2018). Nevertheless, PPA contracts involve complex negotiations to raise project capital, which pose a challenge for community groups to attract investors; the complexity of PPA-based community business models requires expert knowledge and commercial experience (Nolden, Barnes, \& Nicholls; 2020).

Traditionally there are two types of PPA schemes 1) Direct PPA (DPPA) and 2) Virtual PPA (VPPA). As the name suggests, in the DPPA, both developers and buyers are located within the same region, and physical energy is delivered through a grid connection. Direct PPA scheme is the most common type in Europe; it is also called a physical, retail, or sleeved PPA (Schneider Electric, 2019). On the other hand, Virtual PPAs have a flexible structure. Developers and buyers need not be connected through the same grid as there is no physical delivery; instead, a buyer gets renewable energy delivery at the agreed price from a local retailer (WBCSD, 2016). VPPAs has been the norm in the USA; however, it has gained popularity in Europe as well, virtual PPAs are also known as synthetic or financial PPA (Schneider Electric, 2019; WBCSD, 2016). As there is no physical delivery of power; therefore, VPPs cut sleeving costs and provide significant flexibility to the buyer (Schneider Electric, 2019). While selecting a PPA scheme, it is crucial to understand the market context that drives the PPA contracts. Elements such as the contract period, the required volume, demand scenarios, available technology, pricing structure, and subsidy availability influence PPA structure choice (WBCSD, 2018). In recent years, the cost of renewable energy has fallen, resulting in market convergence driven by price parity between green energy and traditional energy. Many utility suppliers are willing to provide green electricity together with PPA contracts; therefore, buyers must be careful in selecting the tariff design before a PPA finalization as they have limited insight into market risks (Schneider Electric, 2020). In the following section, we discuss key elements in a PPA structure that developers and buyers must consider before finalizing a PPA.

\section{Elements in a PPA Model}

\subsection{Tariff Design}

The cost of electricity generated from renewable sources varies across countries; within the European Union, countries have a different unit cost of energy. In the USA, the unit cost of commercial solar energy widely varies between the states of Arizona, California, Massachusetts, and New York (IRENA, 2020). Therefore, developers must know their correct energy cost before negotiating with buyers under a PPA scheme. A matric used in calculating the energy cost for consumers as part of tariff design is called Levelized Cost of Energy (LCOE). In simple terms, it is the average per-unit cost of energy that will be generated during the PPA term covering capital investments and other life cycle costs. LCOE is the product of all the lifetime costs associated with the construction and operation of the energy farms, divided by the electricity produced during this lifetime; LCOE also allows us to compare various generation technologies as each technology might involve different cost elements (World Bank, 2020). In 2019, the average LCOE for commercial PV up to $500 \mathrm{~kW}$ capacity plants for India and China where at $\$ 0.062$ and $\$ 0.064$ per $\mathrm{kWh}$ contrast to UK and France with $\$ 0.187$ and $\$ 0.154$ per $\mathrm{kWh}$; within the USA, Arizona, and New York had a significant difference in LCOE with \$ 0.112 and \$ 0.171 respectively (IRENA, 2020). There are several methodologies to calculate LCOE; Table-1 shows some commonly used models for LCOE calculation.

Table 1. Levelized Cost of Energy (LCOE) models

\begin{tabular}{ccc}
\hline Items & LCOE models & Source \\
\hline
\end{tabular}

Model-1 LCOE $=\left(\sum_{t}^{n} \frac{\mathrm{I}_{t}+\mathrm{M}_{\mathrm{t}}+\mathrm{F}_{\mathrm{t}}}{(1+\mathrm{r})^{\mathrm{t}}}\right) / \sum_{t}^{n}\left(\mathrm{E}_{\mathrm{t}} /(1+\mathrm{r})^{\mathrm{t}}\right)$

(IRERA,2020)

$\mathrm{LCOE}=$ the average lifetime levelised cost of electricity generation, $\mathrm{I}_{\mathrm{t}}=$ investment expenditures in the year $\mathrm{t}, \mathrm{M}_{\mathrm{t}}=$ operations and maintenance expenditures in the year $\mathrm{t}, \mathrm{F}_{\mathrm{t}}=$ fuel expenditures in the year $\mathrm{t}, \mathrm{E}_{\mathrm{t}}=$ electricity generation in the year $\mathrm{t}, \mathrm{r}=$ discount rate, $\mathrm{n}=$ lifetime of the system

Model-2 LCOE $=\left(\sum_{t}^{n} \frac{\text { CAPAX }_{t}+\text { OPEX }_{t}}{(1+r)^{t}}\right) / \sum_{t}^{n}\left(\operatorname{PVOUT}_{t} /(1+\mathrm{r})^{\mathrm{t}}\right)$

$\mathrm{LCOE}=$ the average lifetime levelised cost of electricity generation, $\mathrm{CAPAX}_{\mathrm{t}}=$

(World Bank, Investment expenditures in the year $\mathrm{t}, \mathrm{OPEX}_{\mathrm{t}}=$ Operations and maintenance 2020) expenditures in the year $\mathrm{t}, \mathrm{PVOUT}_{\mathrm{t}}=$ Electricity generation in the year $\mathrm{t}, \mathrm{r}=$ 
Discount rate (WACC), $\mathrm{n}=$ Lifetime of the system.

Model-3

$$
\begin{aligned}
& \mathrm{LCOE}=\left(\sum_{t}^{n} \frac{\left.\mathrm{I}_{+}+\mathrm{M}_{\mathrm{t}}+\mathrm{F}_{\mathrm{t}}+\mathrm{Pen}_{\mathrm{t}}-\mathrm{TC}_{\mathrm{t}}\right) / \sum_{t}^{n}\left(\mathrm{E}_{\mathrm{t}} /(1+\mathrm{r})^{\mathrm{t}}\right)}{(1+\mathrm{r})^{\mathrm{t}}} \mathrm{Pen}_{\mathrm{t}}=\mathrm{Pn}_{\mathrm{t}}+\mathrm{Pl}_{\mathrm{t}}\right. \\
& \mathrm{Pen}_{\mathrm{t}}=\text { Panalety in the year } \mathrm{t}, \mathrm{Pn}_{\mathrm{t}}=\text { Cost of under-deliverying energy in the year } \mathrm{t} \text {, } \\
& \text { when buyer need to cover short supply from external sources, } \mathrm{Pl}_{\mathrm{t}}=\text { Cost of } \\
& \text { over-delivering energy in the year } \mathrm{t} \text {, when buyer not willing to buy excess energy } \\
& \text { delivered, } \mathrm{TC} \mathrm{C}_{\mathrm{t}}=\text { Tax Credit in the year } \mathrm{t} \text {. }
\end{aligned}
$$$$
\text { (Bruck, Sandborn }
$$

Model 1 and 2 (in Table 1) are the primary methods; the LCOE calculated can be compared with the standard retail price of power only. However, one should not use them in a performance-based contract. PPAs are performance agreements, where the buyer places delivery limit requirements. Also, PPAs are used as a risk-sharing strategy; therefore, additional costs must be considered, which are generally not accounted for in the standard LCOE model (Bruck et al., 2018). It essential that LCOE reflects a break-even cost to avoid the developer's risk of project failure and the buyer's risk of price variation and poor delivery. Another critical issue is the Weighted Average Cost of Capital (WACC) that the developer is expected to pay on average to a lender to secure finance for its assets. In general, a WACC of $7.5 \%$ is considered for developed countries and $10 \%$ for the rest of the world. However, the cost of debt and the required return on equity, and the debt-to-equity ratio vary between individual projects and countries, depending on a wide range of factors (IRENA, 2020). Such issues can have a significant impact on the LCOE of the renewable power project. Another critical element in deciding the renewable energy project's economic potential is the capacity factor; in solar energy, it is known as specific yield or Kwh generated per Kw of the peak. A higher value of $\mathrm{kWh}$ per Kwp will result in lower LCOE; therefore, renewable project viability improvers. For commercial solar projects, a range between 3.0 and $5.0 \mathrm{for} \mathrm{kWh} / \mathrm{kWp}$ is considered favorable; average $4.5 \mathrm{kWh} / \mathrm{kWp}$ in the Middle East and North Africa (MENA) region considered most favorable for commercial solar projects (World Bank, 2020). On the contrary, in some western European countries and Japan, due to $\mathrm{kWh} / \mathrm{kWp}$ values below 3.0, the LCOE cost for commercial solar increases (World Bank, 2020).

Having discussed key elements that influence the basic LCOE of renewable energy, we should now account for costs associated with delivery limits and the buyer's performance expectation. The basic LCOE models do not include the effects of the energy delivery limits and their penalty costs imposed by PPAs as a cost to energy generation (Bruck et al., 2018). Model 3 (Table-1) proposed by Bruck et al. (2018) included penalty cost (Pen) and tax benefits (TC). The cost of under-delivering energy (Pn) was considered when generated power for the year was lower than the minimum limit set by the buyer. On the other hand, if the energy generated exceeds the maximum limit, the cost of energy that buyer not willing to buy (Pl) was added to the penalty cost. Bruck et al. (2018) also discounted any tax benefits receivable per local energy policy to reflect a realistic LCOE. Incorporating expected PPA performance characteristics into LCOE permits developers to propose a realistic price model to lenders and assure better visibility on the long-term revenue stream.

\subsection{Bankability and Project Funding}

PPA schemes can provide long-term bankability to renewable energy projects in many European countries (UK and Spain) post FIT withdrawal. In the UK, many community energy organizations are looking to sell electricity to local buyers through the DPPA route for improving the bankability of new projects and securing funds from lenders (Willis and Simcock, 2018). For a renewable energy project under a PPA scheme to be bankable, lenders must have visibility and clarity on how future risks related to price and policy changes are mitigated in the contract. However, there is no single way; these risks can be re-allocated and shared through negotiations depending on the risk appetite of the buyers, developers, and lenders (PwC, 2017). The cash flows in a project are the primary means for debt re-payment; therefore, the developer and buyer must understand the lender's expectations and address them during PPA negotiations (WBCSD, 2016). According to European Bank (2017), bankability does not mean eliminating the risk for the lenders; instead, bankability involves 1) fair allocation of risks among parties, 2) making key elements in contracts more predictable (revenues, role, and responsibilities), 3 ) providing the mechanisms and procedures for addressing risks. The bankability of PPA depends on the contractual terms, its duration, and the buyer's creditworthiness. Additionally, technological innovations such as 
storage and renewable energy mix can improve the predictability and reliability of power generation, thus improving the bankability of the project (WBCSD, 2018).

\subsection{Intermittency and Delivery Terms}

Intermittency of renewable energy has been a significant challenge for project developers in fulfilling agreed PPA performance requirements. Intermittency contributes to project operational risk is a concern for buyers as well; many variables can impact a wind or solar project performance (Schneider Electric, 2020). The main operational risks that are associated with variable generation patterns of wind or solar farms are 1) shape risk, 2) volume risk, and 3) balance risk (WBCSD, 2019). Even if it is possible to forecast the overall volume over a longer period, the generation profile may not match the demand profile on an hour-to-hour basis. In shape risk, the generation profile differs from the demand profile due to varying wind speed or solar irradiation; the buyer would need to work with their third-party electricity supplier to manage the impact of an intermittent output profile interfacing (WBCSD, 2018). In contrast to shape risk, the volume risk is based on a longer time scale, e.g., year-to-year basis where buyer's energy demand may change from agreed volume or developer fails to meet agreed volume requirement in the contract. Under PPA, buyers should finalize their energy procurement strategy considering overall energy usage, load profile, and how this may change over time (PwC, 2017). Balancing risk, applicable to DPPA schemes, is related to system costs that may arise when a facility's forecast generation is different from its actual output. It is common practice to engage a third party, such as a utility or wholesale market trader, to manage any imbalance in the generation (WBCSD, 2019). Technical innovations and strategic partnerships can help developers mitigate risks related to intermittency and delivery terms. The onsite energy storage system can help developers to address shape risk. With Improved technology and a drastic reduction in lithium-ion batteries' cost in recent times, developers can integrate energy storage systems to enhance output flexibility and consistency (WBCSD, 2018). Another strategy to overcome operational risks is to use multi-technology driven energy generation. WBCSD (2019) proposed multi-technology based PPAs involving a mix of wind, solar, biomass, geothermal, or hydro to mitigate operational risks.

\subsection{Project Stakeholders}

PPA is a multi-agency arrangement involving developers, buyers, law firms, lenders, and grid operators. Additionally, equipment suppliers, engineering contractors, and technology providers can play an important role in improving economic performance by adding new values to the project. A PPA contract can be subdivided into multiple sub-contractors such as land contract, balancing contract, installation contract, and operation \& maintenance contracts. Therefore, collaborative learning and information exchange on best practices and lessons learned can improve project success (IRENA, 2018b). Successful renewable energy projects cannot start without forging a partnership between the stakeholders; such partnership can provide opportunities and manifestation to create new values in the project (Odabashian, HassabElnaby \& Manoukian,2019). Ignoring project stakeholder engagements at the early phase of the project can be an opportunity lost for developers in a technology-driven renewable energy project. With a focus on identifying factors improving renewable energy plants' business performance in Indonesia, Mustikaningsih, Cahyandito, Kaltum, and Sarjana (2019) showed strategic partnerships that utilize dynamic capabilities and supply chains play an important role in improving the business performance. The main drivers to create strategic partnerships using dynamic capabilities of other firms are 1) improving reliability of renewable energy systems, 2) revenue sharing and profit maximizations, and 3) reducing the cost of new technologies (Odabashian et al., 2019). 


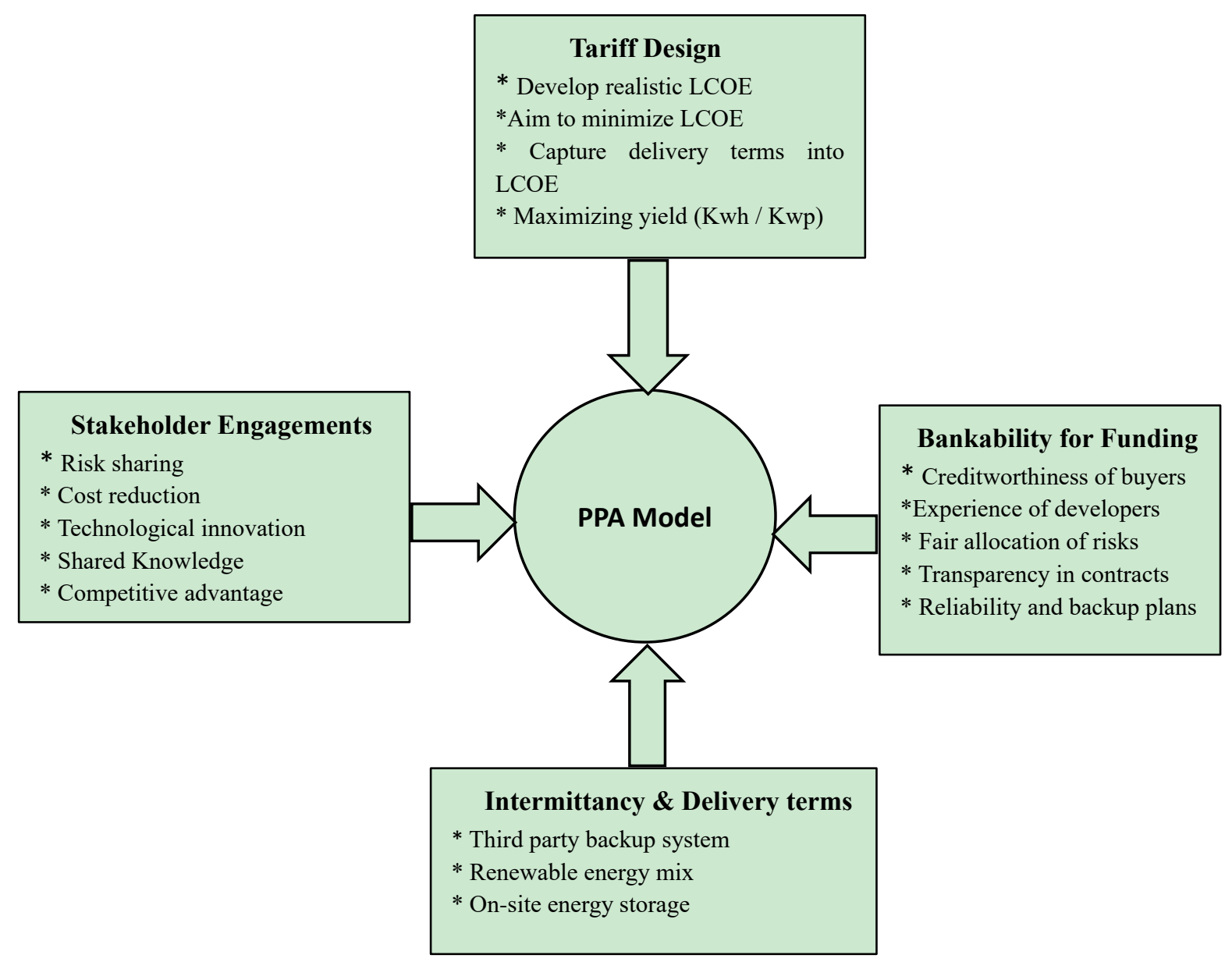

Figure 1. Critical success factors in PPA models

\section{Discussion}

We analyzed critical success factors in a typical PPA model are 1) tariff design, 2) bankability to secure funding, 3) addressing intermittency, and 4) stakeholder engagements. From a developer's perspective, in this section, we aim to discuss the rationale behind PPA model selection, risk mitigation strategies, and strategic business practices to create new values. We also discuss current trends in corporate energy buying and their risk mitigation strategies.

\subsection{Rationale behind PPA Types}

The local energy market's configuration and region-specific policies play a major role in PPA development. At the end of 2017, 35 countries supported PPA activities through market deregulation (IRENA,2018a). Counties such as Argentina, Brazil, Chile, and Mexico developed clear and transparent grid-access policies that permitted both the DPPA and VPPA models and supported the EAC system to incentivize corporate involvement (IRENA,2018a). Within European Union, in France and Germany, where renewable projects receive benefits from public support schemes, they do not receive the EAC system; therefore, corporates are less interested in signing PPAs.In contrast to this, corporations in Netherlands and Sweden have a greater drive for PPAs to receive and claim EACs (Simonelli, 2019). Another important regional driver for PPAs is grid parity; when the cost of renewable electricity generated will be the same or lower than the price of non-renewable electricity available in the grid, many European countries have either achieved or verge of achieving this. According to the UK solar trade association, the LCOE estimate for solar PV in 2019 between $£ 44-70 / \mathrm{MWh}$ set to fall to between $£ 38-£ 54 /$ MWh by 2025; decreasing LCOEs, in tandem with rising electricity prices, creates a promising environment for the diffusion of new subsidy-free projects via PPA route (DLA piper, 2019).

DPPA models are the preferred option when buyers typically have a centralized industrial load that remains constant throughout the term of the contract. The DPPA model either lock-in a fixed price for power with agreed movement during the contract terms or provides a discount to a wholesale power index with a price floor linked to financial hedging instrument against price volatility (Schneider Electric, 2019; WBCSD, 2016). In DPPA 
models, power generation plants are preferably located near a centralized load. However, in many cases, third-party sleeving agents are roped-in when generation assets and buyers are not located nearby but share the same grid network. In this type of arrangement, the buyer ensures that PPA contract terms with the developer, including the transfer of EACs, match those in a separate contract between the buyer and the utility (as sleeving agent) to avoid any delivery related risks (WBCSD, 2016). Rövekamp et al. (2020) highlighted distinct value propositions in favor of DPPA models, 1) locally generated renewable energy fulfills green supply chain requirements and allows consumers to connect well with the renewable origin, and 2) acts as a risk mitigation instrument with a predictable price negotiated between two parties. In addition to industrial buyers, city councils and municipalities also prefer on-site, physical delivery of power via the DPPA route. In the US, the Columbia district's Department in 2015 opted for On-site PPA to avoid transmission and distribution charges associated with off-site PPAs; in similar lines, the Palo Alto utilities (a municipality-owned utility) based in California entered six physical PPAs with solar projects for a total capacity of $153 \mathrm{MW}$ in 2013 (Leung \& Bailey, 2018). The UK has been a leader in PPA development. DPPA structure using sleeving agents is most popular both in the UK and the EU, which resulted in the rapid growth of the market (DLA piper, 2019). Our discussion observed that the DPPA is the most preferred structure for municipalities and government driven PPAs due to long-term price stability and the objective to achieve regional de-carbonization targets. Among developing countries in South America and the Asia Pacific, on-site physical DPPA models are preferred due to lack of market maturity and limited grid connectivity (IRENA, 2018a).

In contrast to physical PPAs, the virtual PPAs provide greater flexibility to buyers who have disaggregated loads and permit them to explore the most competitive price for renewable energy in the larger market beyond the geographical limits (Schneider Electric, 2019). In virtual PPAs, the buyer agrees to power and EAC prices with the developer; a grid operator pays the developer on the delivered power at the variable spot price, and the buyer buys its power from the utility at the same price (WBCSD,2016). The developer and the buyer settle the difference between the variable spot price and the strike price, and the EACs are delivered to the buyer (WBCSD,2016). The VPPA models avoid sleeving costs and allow corporates having operations spread across multiple counties to trade and cancel their EACs in an integrated market. The VPPAs allow corporates to aggregate smaller energy loads under a single umbrella model. The environmental attributes such as GOs or other renewable types certificates obtained from the VPPAs can also be aggregated in the pan-European market (Schneider Electric, 2019). VPPAs are essentially financial hedges or contracts for difference, under which fixed prices are settled against floating or spot prices in the market; depending on the markets, there are many versions of VPPA (PwC, 2017). Due to operational flexibility and access to an integrated market, the VPPAs are the norm for corporates in the USA, and it also started gaining momentum in UK (WBCSD, 2016). Due to the applicability of the supplier hub principle in some member states of European Union, buyers do not have an option to select their energy supplier; therefore, VPPAs can provide more flexibility to buyers (Simonelli, 2019).

\subsection{Risk Mitigation Strategies}

PPA schemes are exposed to multiple risks; market risk, delivery risk, development risk, regulatory risk, and technology risk are major ones. In multi-party contracts such as PPAs, identifying ownership for each type of risk at the beginning of the project is the best means to calculate the risk mitigation cost (Elwakil \& Hegab, 2018). Evaluation of load profile, site location, local policies, and sources of project financing and risk identification and allocation are essential parts of the overall risk management plan in PPAs (PwC, 2017). Fair risk allocation between parties is key in a PPA scheme where the unit cost of energy depends on many external factors. In most government led PPA projects, risks are transferred to private developers, leading to unit cost escalation; instead, when specific risks are transferred, private developers can provide the most competitive unit price (Elwakil \& Hegab, 2018). 
Table 2. Risk management strategies in PPA models

\begin{tabular}{|c|c|c|c|}
\hline Risk category & Risk types & Mitigation strategies & Sources \\
\hline
\end{tabular}

\begin{tabular}{|c|c|c|c|}
\hline Market risk & Price risk & $\begin{array}{l}\text {-Fixed price with agreed escalation } \\
\text {-Cape and floor limits for the entire } \\
\text { term } \\
\text {-Hedging instruments against spot } \\
\text { price }\end{array}$ & (WBCSD, 2016, 2018) \\
\hline Delivery risk & $\begin{array}{l}\text {-Shape risk } \\
\text {-Volume risk } \\
\text {-Balance risk }\end{array}$ & $\begin{array}{l}\text { - Third party (on-site energy stoage) } \\
\text { - Technology mix } \\
\text { - Third pary (energy supplier to } \\
\text { buyer) }\end{array}$ & (WBCSD, 2018, 2019) \\
\hline $\begin{array}{l}\text { Development } \\
\text { risk }\end{array}$ & $\begin{array}{l}\text {-Cost escalation } \\
\text {-Project delays }\end{array}$ & $\begin{array}{l}\text { - Indemnity with contractors / } \\
\text { suppliers } \\
\text { - Risk transfer through partnership } \\
\text { - Milestone linked payment }\end{array}$ & $\begin{array}{l}\text { (Elwakil \& Hegab, 2018), } \\
\text { (Odabashian et al., 2019) }\end{array}$ \\
\hline $\begin{array}{l}\text { Regulatory } \\
\text { risk }\end{array}$ & $\begin{array}{l}\text {-Regulation } \\
\text { change } \\
\text {-Change in LCOE }\end{array}$ & $\begin{array}{l}\text { - Workable provisions in PPA } \\
\text { contract } \\
\text { - Early involvement of law firms } \\
\text { /consultants } \\
\text { - Incorporate expected regulatory } \\
\text { change secenarios in financial model } \\
\text { for future adjustments }\end{array}$ & $\begin{array}{l}\text { (WBCSD, 2018) } \\
\text { (PwC,2017) } \\
\text { (Elwakil \& Hegab, 2018) } \\
\text { (DLA piper, 2019). }\end{array}$ \\
\hline $\begin{array}{l}\text { Technology } \\
\text { risk }\end{array}$ & $\begin{array}{l}\text {-Intermittency } \\
\text {-Increase in O\&M } \\
\text { cost }\end{array}$ & $\begin{array}{l}\text {-Technology mix (Wind, Solar etc) } \\
\text {-Innovative solutions through } \\
\text { partnerships } \\
\text {-Risk sharing / transfer to O\&M } \\
\text { contractors }\end{array}$ & $\begin{array}{l}\text { (WBCSD, 2018) } \\
\text { (Odabashian et al., 2019) }\end{array}$ \\
\hline
\end{tabular}

In a subsidy-free environment, lenders always look for the most optimum debt-to-equity ratio to ensure healthy cash flow. From the developer's perspective, a debt-to-equity ratio must be maintained at an optimum level. Without FIT supports, lenders expect a higher share of equity to make the viable business case in PPA; the debt-to-equity ratio (80:20) of the subsidy era is likely to change to 60:40 in a subsidy-free environment (Ryszka, 2020). The cash flows of the project are the primary means for repayment of that debt; therefore, developers must sufficiently mitigate default risks to ensure cash flows (WBCSD,2016). However, In the PPA model, developers often struggle to strike a balance between the most competitive tariff expected by buyers and a higher return on investment expected by equity investors. The three factors that negatively affect the debt - to - equity ratio are 1) lower PPA prices, 2) contracting partial electricity produced, and 3) shorter PPA tenors while, it is positively affected by the decrease of capital and operational expenditure of renewable energy projects (Ryszka, 2020). In the last five years, there has been significant demand for innovative hedging products in the market. Many tailor-made insurance products are available for both developers and buyers to safeguard them against uncertainty. Proxy revenue swaps have recently emerged in the renewable energy market; it has the potential to evolve into a crucial cost-effective tool to accelerate corporate PPA deployment (WBCSD, 2018).

Although renewable energy cost is significantly reduced in the last few years due to lower technology costs and overall Capex cost of renewable projects. However, the corporate buyer often faces uncertainty about energy 
price variation against the strike price $(\mathrm{PwC}, 2017)$. Corporate buyers have traditionally used hedging solutions to address volatility in energy prices. Using commodity markets, corporate buyers can use trading platforms in energy exchange to manage price risk. The creditworthiness of corporate buyers is a critical factor in improving bankability in the PPA model. A multi-buyer structure has emerged for buyers who want to manage their credit risk; buyer's club structures can help spread credit risk. The Krammer onshore wind project in the Netherlands benefited from buyer's club structures (Google, DSM, AkzoNobel, and Philips), which allowed project financiers to manage the counterparty risk in an effective way (WBCSD, 2018). Each buyer had identical PPA terms, with a scenario whereby one or more buyers could exit the transaction or become insolvent by way of a requirement for the other buyers to take up the shortfall or source an alternative corporate buyer (WBCSD, 2018).

\subsection{Strategic Partnerships for Value Creation}

In contrast to the conventional energy market, the PPA is a naïve market driven by local and regional factors; therefore, developers often face several business uncertainties and challenges. Low-cost renewable energy has been the main driver for buyers to explore the PPA market. From a developer's perspective, the LCOE must be as low as possible to win a PPA contract; also, at the same time, they must have enough earnings to repay their debts. In a renewable energy project, certain drivers push diverse stakeholders to form strategic partnerships for the project's success; such drivers could vary with the size and type of projects (Odabashian et al., 2019). One of the drivers is to create a competitive advantage utilizing the dynamic capabilities of other organizations (Mustikaningsih et al., 2019). RE projects usually high upfront capital. Odabashian et al. (2019), in a case study, found that financial mechanism was one of the drivers for a strategic partnership where developers in Arizona and Kansas collaborated with financers and investment bankers to secure gap fundings. Another important driver is renewable energy cost-competitiveness in comparison to conventional energy. According to Odabashian et al. (2019), all respondents in the case study highlighted technology cost-competitiveness as an important factor and collaborated with suppliers and technology providers to pursue profit maximization by cutting costs. The application of technological innovations to create new renewable energy projects is another important driver for the strategic partnership. With new developments in on-site energy storage and lithium-ion batteries' falling cost, many developers make a strategic alliance with solution providers. Proka et al. (2020) studied the collaborative business models in energy storage based on a collaboration between a dutch based Energy supply operator, energy consumers, and energy storage providers. Proka et al. (2020) found the main aim of integrating energy storage solutions, managed and operated by a third party, was to improve the reliability, flexibility, and affordability of decentralized energy systems. According to WBCSD (2019), using multiple renewable technologies (mix of solar, wind, etc.) backed with on-site battery storage solutions can help developers address delivery-related risks. In addition to technological innovations, several innovative concepts in risk management and project financing have emerged. Among them is proxy revenue swaps, where a hedge provider with a specific risk appetite willing to make investments that are correlated with natural phenomena such as intermittency due to a weather risk (WBCSD, 2019). To minimize transaction costs and lower the LCOE for solar power, IRENA (2018b) advocated designing a standard contractual framework that can be used as a simplified tool to balance risk allocation and reduce project development time. Such an attempt to bring-in a standardization in the PPA framework is a welcome step; however, developers' abilities to forge strategic partnerships in PPAs should not be restricted in this standardization process.

\section{Conclusion}

This paper aimed to contribute to the existing knowledge on PPAs by analyzing critical success factors in the PPA model. We analyzed four critical success factors, 1) tariff design, 2) bankability to secure funds, 3) addressing intermittency and delivery terms, and 4) stakeholder engagement. We also discussed the importance of designing a realistic LCOE model incorporating delivery restrictions imposed by buyers. During the analysis, it was evident that the PPA concept is a novice and still evolving; the selection of the PPA model depends on regional settings and local energy policies. PPAs are a complex arrangement of multiple entities (developers, buyers, lenders, etc.) involving various types of risks; therefore, it is essential that risk allocation to each entity is fair and risk mitigation cost is justified. Finally, we observed developers initiate strategic partnerships to add value to the PPAs. The falling cost of renewable energy and increasing competition in the PPA market have necessitated developers to achieve competitive advantage through a strategic partnership.

\section{References}

Acharya, A., \& Cave L. A. (2020). Feed-in-Tariff Removal in UK's Community Energy: Analysis and Recommendations for Business Practices. Journal of Sustainable Development, 13(4), 1-14. 
https://doi.org/10.5539/jsd.v13n4p1

Bruck, M., Sandborn, P., \& Goudarzi, N. (2018). A Levelized Cost of Energy (LCOE) model for wind farms that include Power Purchase Agreements (PPAs). Renewable Energy, 122, 131-139. https://doi.org/10.1016/j.renene.2017.12.100

DLA piper (2019). Europe's subsidy-free transition and grid parity. Retrieved from https://www.dlapiper.com/it/italy/insights/publications/2019/12/europes-subsidy-free-transition/

Elwakil, E., \& Hegab, M. (2018, November). Risk management for power purchase agreements. In 2018 IEEE Conference on Technologies for Sustainability (SusTech),1-6. https://doi.org/ 10.1109/SusTech.2018.8671337

European Bank (2017, March). Template contract for financing renewable energy projects. Retrieved from https://energy-community.org/dam/jcr:55e439e0-0c19-4ea8-8649126770c873e7/RECG032017_European\% 20Bank.pdf

Fuentes-Bracamontes, R. (2016). Is unbundling electricity services the way forward for the power sector? The Electricity Journal, 29(9), 16-20. https://doi.org/10.1016/j.tej.2016.10.006

IRENA (2018a). Corporate sourcing of renewable energy: Market and industry trends. Retrieved from https://www.irena.org/publications/2018/May/Corporate-Sourcing-of-Renewable-Energy

IRENA (2018b). Power purchase agreements for variable renewable energy. Retrieved from https://www.irena.org/-/media/Files/IRENA/Agency/Events/2018/Aug/Renewable-Energy-PPAs.pdf?la=en\&hash $=$ C365D5D08EBFF26A1F7A29A13D721C5B3C4390D9

IRENA (2020). Renewable power generation costs in 2019. Retrieved from https://www.irena.org/publications/2020/Jun/Renewable-Power-Costs-in-2019

Leung, J., \& Bailey, A. (2018). How cities benefit from power purchase agreements. Center for Climate and Energy Solutions. $\quad$ Retrieved from https://www. org/site/assets/uploads/2018/09/how-cities-benefit-from-ppas. pdf.

Mustikaningsih, D., Cahyandito, M. F., Kaltum, U., \& Sarjana, S. (2019). Building business performance through partnership strategy model: Evidence from renewable energy industry in Indonesia. International Journal of Energy Economics and Policy, 9(5), 297-307. https://doi.org/10.32479/ijeep.7780

Odabashian, V., HassabElnaby, H. R., \& Manoukian, A. (2019). Innovative renewable energy technology projects' success through partnership. International Journal of Energy Sector Management, 13(2), 341-358. https://doi.org/10.1108/IJESM-04-2018-0001

PwC (2017). Optimising energy procurement via corporate PPAs. Retrieved from https://www.pwc.com.au/publications/pdf/optimising-energy-corporate-ppas-nov17.pdf

Nolden, C., Barnes, J., \& Nicholls, J. (2020). Community energy business model evolution: A review of solar photovoltaic developments in England. Renewable and Sustainable Energy Reviews, 122, 109722. https://doi.org/10.1016/j.rser.2020.109722

Proka, A., Hisschemöller, M., \& Loorbach, D. (2020). When top-down meets bottom-up: Is there a collaborative business model for local energy storage? Energy Research \& Social Science, 69, 101606. https://doi.org/10.1016/j.erss.2020.101606

Rövekamp, P., Schöpf, M., Wagon, F., Weibelzahl, M., \& Fridgen, G. (2020). Renewable electricity business models in a post feed-in tariff era. Energy, 216, 119228. https://doi.org/10.1016/j.energy.2020.119228

Ryszka, K., (2020, January). Renewable project finance: Can corporate PPAs replace renewable energy subsidies? Rabobank/RaboResearch, Utrecht. Retrieved from https:/economics.rabobank.com/publications/2020/january/renewable-project-finance-corporate-PPA/

Schneider Electric (2020) Renewable energy in europe proactively managing risks. Retrieved from https://perspectives.se.com/renewable-energy/proactively-managing-risks-to-accomplish-long-term-energygoals-using-renewable-ppas

Schneider Electric (2019). Exploring-renewable-energy-ppas-in-europe. Retrieved from https://perspectives.se.com/renewable-energy/exploring-renewable-ppas-in-europe

Simonelli, F., (2019). Competitiveness of corporate sourcing of renewable energy Part 2 of the Study on the competitiveness of the renewable energy sector Final report. European Commission, Brussels. Retrieved 
from https://www.ceps.eu/wp-content/uploads/2019/09/MJ0219620ENN.en-1.pdf

WBCSD (2016). Corporate renewable power purchase agreements: Scaling up globally. Retrieved from https://www.wbcsd.org/Programs/Climate-and

Energy/Climate/Resources/Corporate_Renewable_PPAs_Scaling_up_globally

WBCSD (2018). Innovation in power purchase agreement structures. Retrieved from https://www.wbcsd.org/Programs/Climate-and-Energy/Energy/REscale/Resources/Innovation-in-Power-Pur chase-Agreement-Structures

WBCSD (2019). How multi-technology PPA structures could help companies reduce risk. Retrieved from https://www.wbcsd.org/Programs/Climate-and-Energy/Energy/REscale/Resources/How-multi-technology-P PAs-could-help-companies-reduce-risk

Willis, R., \& Simcock, N. (2019) Consumer (Co-)ownership of renewables in England and Wales (UK). In Lowitzsch J. (Eds.), Energy transition (pp. 369-394). https://doi.org/10.1007/978-3-319-93518-8_17

World Bank (2020). Global photovoltaic power potential by country. Retrieved from https://www.worldbank.org/en/topic/energy/publication/solar-photovoltaic-power-potential-by-country

\section{Copyrights}

Copyright for this article is retained by the author(s), with first publication rights granted to the journal.

This is an open-access article distributed under the terms and conditions of the Creative Commons Attribution license (http://creativecommons.org/licenses/by/4.0/). 